\title{
Sequential free right internal thoracic artery grafting for multivessel coronary artery bypass grafting
}

\author{
Toshihiro Fukui, MD, ${ }^{\mathrm{a}}$ Minoru Tabata, MD, MPH, ${ }^{\mathrm{a}}$ Satoshi Morita, MD, $\mathrm{PhD},{ }^{\mathrm{b}}$ and \\ Shuichiro Takanashi, MD ${ }^{\mathrm{a}}$
}

\begin{abstract}
Objectives: This study compared early and follow-up angiographic results of individual and sequential grafting with the free right internal thoracic artery (RITA).

Methods: We reviewed 334 patients who underwent multivessel coronary artery bypass grafting with the free RITA between September 2004 and December 2010. The free RITA was used for individual grafting in 179 patients and for sequential grafting in 155 patients. We compared operative and postoperative variables and early and follow-up angiographic patency rates of distal anastomoses of the free RITA between the groups.
\end{abstract}

Results: The mean number of distal anastomoses in sequential grafting was $2.2 \pm 0.4$. The inflow of the free RITA included the aorta $(27.4 \%)$ and other grafts $(72.6 \%)$ in the individual group. The inflow of free RITA was exclusively other grafts in the sequential group. Operative mortality and incidence of postoperative complications were not significantly different between groups. Overall patency rate of distal anastomosis of the free RITA was $99.1 \%$ at early angiography and $91.8 \%$ at follow-up angiography, and the rate did not differ significantly between individual and sequential grafting (early, $98.6 \%$ vs $99.3 \%$; follow-up, $93.0 \%$ vs $91.2 \%$ ).

Conclusions: Multivessel coronary artery bypass grafting with the free RITA is safe and useful. Patency rates of distal anastomoses are similar between individual and sequential grafting with the free RITA at early and followup angiography. When the RITA cannot be used as an in situ graft for multiple anastomoses, sequential grafting with the free RITA should be considered. (J Thorac Cardiovasc Surg 2012;144:824-9)

Internal thoracic artery (ITA) grafts have the most favorable patency and durability among the conduits used for coronary artery bypass grafting. ${ }^{1}$ Observational studies have demonstrated that the use of bilateral ITA grafts provides better survival benefits than does the use of single ITA grafts. $^{2}$ The left ITA (LITA) has predominantly been used for the revascularization of the left anterior descending coronary artery. On the other hand, the right ITA (RITA) has usually been used for the second or third most important coronary artery on the left side. The RITA has the flexibility of use as an in situ or free graft. Recently, Tatoulis and colleagues $^{3}$ and other investigators ${ }^{4,5}$ have reported that in situ RITA and free RITA grafts have similar patency rates. A free RITA graft can be used for more distal territory than in situ RITA graft, and it is used for sequential multiple grafting. Sequential grafting with the free RITA has not frequently been performed, however, because of the complexity and a lack of angiographic information.

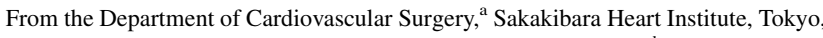
Japan; and the Department of Biostatistics and Epidemiology, ${ }^{\mathrm{b}}$ Yokohama City University Medical Center, Yokohama, Japan.

Disclosures: Authors have nothing to disclose with regard to commercial support. Received for publication July 22, 2011; revisions received Oct 17, 2011; accepted for publication Nov 9, 2011; available ahead of print Dec 12, 2011.

Address for reprints: Toshihiro Fukui, MD, Department of Cardiovascular Surgery, Sakakibara Heart Institute, 3-16-1 Asahi-cho, Fuchu City, Tokyo 183-0003, Japan (E-mail: tfukui.cvs@gmail.com).

0022-5223/\$36.00

Copyright (c) 2012 by The American Association for Thoracic Surgery doi:10.1016/j.jtcvs.2011.11.021
}

The aim of this study was to compare early and follow-up angiographic results between individual and sequential grafting with a free RITA graft.

\section{MATERIALS AND METHODS \\ Patient Population}

Between September 2004 and December 2010, a total of 1236 patients underwent isolated coronary artery bypass grafting at Sakakibara Heart Institute, Tokyo, Japan. The RITA was used in 1095 patients. Among these, the free RITA was used in 334 patients $(27.0 \%)$. Preoperative characteristics of these 334 patients are shown in Table 1. We prefer to use the free RITA for revascularization of diagonal branch and left circumflex artery territories. We applied multiple sequential grafting with the free RITA in patients with a limited number of grafts. When we anastomosed the free RITA to the ascending aorta, we routinely used intraoperative epiaortic echocardiography to detect a disease-free area of the aorta. When we anastomosed the free RITA proximally to another graft (LITA, radial artery, or saphenous vein graft), we created a Y-shaped composite graft.

The strategy for using either individual or sequential grafting with the free RITA was as follows: (1) Individual grafting was used for single large lateral vessels (in patients in whom the in situ RITA was not reachable). (2) Individual grafting was used for anterior vessels in patients whose LITA was used for lateral vessels (in patients in whom the in situ RITA was not reachable). (3) Sequential grafting was used for 2 or more similarly sized lateral vessels.

\footnotetext{
Operation

Operations were performed by 3 surgeons (S.T., T.F., M.T.) who all used the same strategy and technique. Our strategy for isolated coronary artery bypass grafting was directed toward obtaining complete myocardial revascularization with an off-pump technique whenever feasible. The operative technique of off-pump coronary artery bypass grafting has been described
} 


\section{Abbreviations and Acronyms \\ ITA = internal thoracic artery \\ LITA $=$ left internal thoracic artery \\ RITA $=$ right internal thoracic artery}

previously. ${ }^{6}$ All arterial grafts were harvested in a skeletonized fashion with an ultrasonic scalpel (Harmonic Scalpel; Ethicon Endo-Surgery, Inc, Blue Ash, Ohio). The RITA was taken down after milrinone solution $(50 \mathrm{mg} / \mathrm{L})$ had been injected into the distal end. The free RITA was harvested in a skeletonized fashion and preserved in a warm milrinone solution $(10,000 \mathrm{U}$ heparin and $10 \mathrm{mg}$ milrinone in $1000 \mathrm{~mL}$ of normal saline solution). We bypassed all significantly diseased coronary vessels (at least a $50 \%$ diameter reduction) larger than $1 \mathrm{~mm}$ in diameter. When sequential grafting was constructed, diamond-shaped side-to-side anastomoses and terminal T-shaped anastomoses were our preferred approaches. If necessary, the anastomosis was rotated in accordance with the angle between the graft and vessels. After all distal anastomoses were completed, anastomosis between the donor and the free RITA was performed at the end of the procedure. We performed extensive reconstruction when the left anterior descending coronary artery was diffusely diseased and its branches, such as septal and diagonal arteries, were affected by severe atheromatous plaques. The detailed indication, technique, and outcomes of long segmental reconstruction of the left anterior descending coronary artery have been described previously elsewhere. ${ }^{7}$

\section{Angiography}

Early postoperative angiography was performed in 270 patients $(80.8 \%)$, all of whom gave their informed consent. The median time of early postoperative angiography was 10 days after surgery (range, 1-20 days). If patients began to have symptoms during follow-up, diagnostic angiography was performed at that time. Unless patients showed symptoms within 1 year after surgery, follow-up angiography was performed 1 year after surgery. Follow-up postoperative angiography was performed for 170 patients $(50.9 \%)$, and the median time was 12.1 months after surgery (range, 2-21 months).

We compared the preoperative, intraoperative, postoperative, and angiographic variables between patients who underwent individual free RITA grafting and those who underwent sequential grafting. All data were collected prospectively and reviewed retrospectively. The institutional review board of Sakakibara Heart Institute approved this retrospective study and waived the need for written consent.

Nonelective operations included both emergency and urgent cases according to the definitions used in the Society of Thoracic Surgeons database. Operative death was defined as death occurring during the same hospitalization or after discharge from the hospital but within 30 days of the procedure. Low-output syndrome was defined as the postoperative need for any dose of epinephrine or for more than $5 \mu \mathrm{g} /(\mathrm{kg} \cdot \min )$ of dopamine hydrochloride (INN dopamine) or dobutamine. Perioperative myocardial infarction was defined as a positive result for new $\mathrm{Q}$ waves in an electrocardiogram or a peak creatine kinase MB level of greater than or equal to 5 times the upper limit of normal (25 IU/L). Respiratory failure was defined as the requirement of prolonged ventilation ( $>48$ hours) or the presence of pneumonia. A postoperative stroke was defined as the occurrence of a new stroke and was confirmed by computed tomography. In patients with preoperative stroke, postoperative stroke was defined as a worsening of the neurologic deficit with new radiologic findings.

A patent graft anastomosis was defined as an anastomosis without occlusion, significant stenosis $(>90 \%)$, or string sign of the graft near the anastomosis. String sign was defined as luminal narrowing of the graft, including stenosis of $90 \%$ or greater.
Early and follow-up patency rates were calculated by dividing the number of patent anastomoses by the total number of anastomoses. For patients with early nonpatent anastomoses who underwent a follow-up angiogram, those nonpatent anastomoses were also counted as follow-up nonpatent anastomoses.

Early and follow-up patency rates of the free RITA were also compared with those of other grafts used in the study patients. Furthermore, early and follow-up patency rates of the free RITA were compared with those of the in situ RITA used in 761 patients.

\section{Statistical Analysis}

All statistical analyses were performed with StatView 5.0 software (SAS Institute Inc, Cary, NC). Continuous variables are reported as mean $\pm \mathrm{SD}$. Continuous variables were compared with the Student $t$ test, whereas discrete variables were compared with the $\chi^{2}$ test or Fisher's exact test. For comparison of graft patency, we performed generalized estimating equations in addition to the $\chi^{2}$ test to adjust for patient cluster effects. Actuarial event-free survival curves were estimated by the Kaplan-Meier method. The log-rank test was used to assess whether there were differences in survival between subject groups.

\section{RESULTS}

\section{Clinical Outcomes}

Preoperative characteristics of both groups are shown in Table 1 . The rate of triple-vessel disease was significantly higher in the sequential grafting group than in the individual grafting group. There was a significantly larger number of patients who had a previous myocardial infarction in the sequential grafting group than in the individual grafting group $(P=.0377)$.

Target vessels used for the free RITA are listed in Table 2. In the individual grafting group, the proximal anastomosis site of the free RITA was the aorta in 49 patients $(27.4 \%)$, the LITA in 29 patients $(16.2 \%)$, and other grafts (radial artery or saphenous vein graft) in 101 patients $(56.4 \%)$. In the sequential grafting group, the proximal anastomosis site of the free RITA was the LITA in 78 patients $(50.3 \%)$ and other grafts (radial artery or saphenous vein graft) in $77 \mathrm{pa}-$ tients $(49.7 \%)$.

Operative and postoperative variables are listed in Table 3. The mean number of distal anastomoses per patient was larger in the sequential grafting group than in the individual grafting group $(P<.0001)$. Other grafts used in the 2 groups are listed in Table 3 . The operation time in the sequential grafting group tended to be longer than that in the individual grafting group, but this difference was not statistically significant $(P=.0644)$. The operative mortality and the incidence of postoperative complications were not significantly different between the groups.

During the follow-up period, there were 13 deaths, other than operative deaths, among the 334 patients. There were 4 deaths (acute aortic dissection, pneumonia, cancer, and sudden death) in the individual group and 9 deaths (stroke, intracranial hemorrhage, cancer, congestive heart failure in 2 patients, pneumonia in 2 patients, renal failure, and sudden death) in the sequential group. Figure 1, $A$ shows that there was no difference in midterm survival between the groups 
TABLE 1. Preoperative characteristics of patients with a free right internal thoracic artery graft

\begin{tabular}{|c|c|c|c|c|}
\hline & All $(\mathbf{n}=334)$ & Individual $(\mathbf{n}=179)$ & Sequential $(n=155)$ & $P$ value \\
\hline Age $(y$, mean $\pm S D)$ & $67.2 \pm 10.4$ & $67.0 \pm 10.7$ & $67.4 \pm 10.0$ & .7731 \\
\hline Sex (No. female) & $65(19.5 \%)$ & $42(23.5 \%)$ & $23(14.8 \%)$ & .0647 \\
\hline Body surface area $\left(\mathrm{m}^{2}\right.$, mean $\left.\pm \mathrm{SD}\right)$ & $1.6 \pm 0.2$ & $1.6 \pm 0.2$ & $1.6 \pm 0.2$ & .9042 \\
\hline Unstable angina (no.) & $85(25.4 \%)$ & $51(28.5 \%)$ & $34(21.9 \%)$ & .2128 \\
\hline Canadian Cardiovascular Society class (mean $\pm \mathrm{SD}$ ) & $2.2 \pm 0.8$ & $2.2 \pm 0.8$ & $2.2 \pm 0.8$ & .6526 \\
\hline Ejection fraction $(\%$, mean $\pm \mathrm{SD})$ & $55.4 \pm 11.7$ & $56.3 \pm 11.6$ & $54.4 \pm 11.7$ & .1343 \\
\hline Extent of disease & & & & .0288 \\
\hline Single-vessel disease (no.) & $3(0.9 \%)$ & $2(1.1 \%)$ & $1(0.6 \%)$ & - \\
\hline Double-vessel disease (no.) & $43(12.9 \%)$ & $31(17.3 \%)$ & $12(7.7 \%)$ & - \\
\hline Triple-vessel disease (no.) & $288(86.2 \%)$ & $146(81.6 \%)$ & $142(91.6 \%)$ & - \\
\hline Left main disease (no.) & $111(33.2 \%)$ & $60(33.5 \%)$ & $51(32.9 \%)$ & $>.9999$ \\
\hline Creatinine $(\mathrm{mg} / \mathrm{dL}$, mean $\pm \mathrm{SD})$ & $1.2 \pm 1.6$ & $1.2 \pm 1.6$ & $1.3 \pm 1.7$ & .4520 \\
\hline Congestive heart failure (no.) & $53(15.9 \%)$ & $23(12.8 \%)$ & $30(19.4 \%)$ & .1408 \\
\hline Previous myocardial infarction (no.) & $151(45.2 \%)$ & $71(39.7 \%)$ & $80(51.6 \%)$ & .0377 \\
\hline Hypertension (no.) & $230(68.9 \%)$ & $117(65.4 \%)$ & $113(72.9 \%)$ & .1721 \\
\hline Diabetes mellitus (no.) & $168(50.3 \%)$ & $85(47.5 \%)$ & $83(53.5 \%)$ & .3196 \\
\hline Insulin therapy (no.) & $47(14.1 \%)$ & $26(14.5 \%)$ & $21(13.5 \%)$ & .9217 \\
\hline Hyperlipidemia (no.) & $220(65.9 \%)$ & $123(68.7 \%)$ & $97(62.6 \%)$ & .2876 \\
\hline Smoking (no.) & $212(63.5 \%)$ & $110(61.5 \%)$ & $102(65.8 \%)$ & .4776 \\
\hline Previous stroke (no.) & $38(11.4 \%)$ & $18(10.1 \%)$ & $20(12.9 \%)$ & .5192 \\
\hline Peripheral vascular disease (no.) & $31(9.3 \%)$ & $15(8.4 \%)$ & $16(10.3 \%)$ & .6737 \\
\hline Chronic obstructive pulmonary disease (no.) & $16(4.8 \%)$ & $11(6.1 \%)$ & $5(3.2 \%)$ & .3226 \\
\hline Nonelective surgery (no.) & $22(6.6 \%)$ & $12(6.7 \%)$ & $10(6.5 \%)$ & $>.9999$ \\
\hline Previous percutaneous coronary intervention (no.) & $104(31.1 \%)$ & $57(31.8 \%)$ & $47(30.3 \%)$ & .8564 \\
\hline Reoperative procedure & $11(3.3 \%)$ & $7(3.9 \%)$ & $4(2.6 \%)$ & .5539 \\
\hline
\end{tabular}

TABLE 2. Target vessels of the free right internal thoracic artery graft

\begin{tabular}{|c|c|c|c|c|}
\hline & Target vessel 1 & Target vessel 2 & Target vessel 3/4 & No. \\
\hline \multirow[t]{5}{*}{ Individual } & & & & 179 \\
\hline & LAD & & & 19 \\
\hline & Diagonal & & & 11 \\
\hline & Obtuse marginal & & & 42 \\
\hline & Left posterolateral & & & 97 \\
\hline \multirow[t]{8}{*}{ Sequential (double) } & & & & 127 \\
\hline & Diagonal & LAD & & 4 \\
\hline & & Diagonal & & 5 \\
\hline & & Obtuse marginal & & 12 \\
\hline & & Left posterolateral & & 11 \\
\hline & Obtuse marginal & Obtuse marginal & & 2 \\
\hline & & Left posterolateral & & 61 \\
\hline & Left posterolateral & Left posterolateral & & 32 \\
\hline \multirow[t]{7}{*}{ Sequential (triple) } & & & & 26 \\
\hline & Diagonal & Diagonal & Obtuse marginal & 3 \\
\hline & & Obtuse marginal & Left posterolateral & 6 \\
\hline & & Left posterolateral & Left posterolateral & 3 \\
\hline & Obtuse marginal & Obtuse marginal & Left posterolateral & 4 \\
\hline & & Left posterolateral & Left posterolateral & 6 \\
\hline & Left posterolateral & Left posterolateral & Left posterolateral & 4 \\
\hline \multirow[t]{2}{*}{ Sequential (quadruple) } & & & & 2 \\
\hline & Diagonal & Obtuse marginal & Left posterolateral $\times 2$ & 2 \\
\hline
\end{tabular}

$L A D$, Left anterior descending coronary artery. 
TABLE 3. Operative and postoperative data of patients with a free right internal thoracic artery graft

\begin{tabular}{|c|c|c|c|c|}
\hline & All $(\mathbf{n}=\mathbf{3 3 4})$ & Individual $(\mathbf{n}=179)$ & Sequential $(n=155)$ & $P$ value \\
\hline Anastomoses per patient (mean \pm SD) & $4.4 \pm 1.1$ & $3.8 \pm 1.0$ & $5.0 \pm 1.0$ & $<.0001$ \\
\hline Anastomoses of right ITA per patient (mean $\pm \mathrm{SD}$ ) & $1.6 \pm 0.7$ & 1.0 & $2.2 \pm 0.4$ & $<.0001$ \\
\hline Grafts per patient $($ mean $\pm \mathrm{SD})$ & $3.4 \pm 0.6$ & $3.4 \pm 0.7$ & $3.3 \pm 0.6$ & .5907 \\
\hline Use of left ITA (no.) & $331(99.1 \%)$ & $176(98.3 \%)$ & $155(100 \%)$ & .2516 \\
\hline Use of radial artery (no.) & $50(15.0 \%)$ & $27(15.1 \%)$ & $23(14.8 \%)$ & $>.9999$ \\
\hline Use of gastroepiploic artery (no.) & $18(5.4 \%)$ & $9(5.0 \%)$ & $9(5.8 \%)$ & .9432 \\
\hline Use of saphenous vein graft (no.) & $281(84.1 \%)$ & $149(83.2 \%)$ & $132(85.2 \%)$ & .7421 \\
\hline Extensive reconstruction of LAD (no.) & $82(24.6 \%)$ & $43(24.0 \%)$ & $39(25.2 \%)$ & .9095 \\
\hline Complete revascularization (no.) & $320(95.8 \%)$ & $171(95.5 \%)$ & $149(96.1 \%)$ & $>.9999$ \\
\hline Off-pump procedure (no.) & $317(94.9 \%)$ & $171(95.5 \%)$ & $146(94.2 \%)$ & .7604 \\
\hline Operation time (min, mean $\pm \mathrm{SD}$ ) & $293.3 \pm 58.7$ & $287.7 \pm 59.7$ & $299.7 \pm 57.1$ & .0644 \\
\hline Transfusion (no.) & $120(35.9 \%)$ & $67(37.4 \%)$ & $53(34.2 \%)$ & .6167 \\
\hline Intubation $(\mathrm{h}$, mean $\pm \mathrm{SD})$ & $8.8 \pm 11.1$ & $9.5 \pm 14.5$ & $8.1 \pm 4.6$ & .2620 \\
\hline Intensive care unit stay $(\mathrm{d}$, mean $\pm \mathrm{SD})$ & $1.4 \pm 1.3$ & $1.4 \pm 1.5$ & $1.4 \pm 1.0$ & .9706 \\
\hline Operative death (no.) & $3(0.9 \%)$ & $1(0.6 \%)$ & $2(1.3 \%)$ & .5988 \\
\hline Reexploration for bleeding (no.) & $7(2.1 \%)$ & $3(1.7 \%)$ & $4(2.6 \%)$ & .7085 \\
\hline Low-output syndrome (no.) & $4(1.2 \%)$ & $1(0.6 \%)$ & $3(1.9 \%)$ & .3406 \\
\hline Perioperative myocardial infarction (no.) & $4(1.2 \%)$ & $2(1.1 \%)$ & $2(1.3 \%)$ & $>.9999$ \\
\hline Severe ventricular arrhythmia (no.) & $3(0.9 \%)$ & $2(1.1 \%)$ & $1(0.6 \%)$ & $>.9999$ \\
\hline Atrial fibrillation (no.) & $72(21.6 \%)$ & $43(24.0 \%)$ & $29(18.7 \%)$ & .2964 \\
\hline Requirement of hemodialysis (no.) & $5(1.5 \%)$ & $2(1.1 \%)$ & $3(1.9 \%)$ & .6662 \\
\hline Stroke (no.) & $4(1.2 \%)$ & $3(1.7 \%)$ & $1(0.6 \%)$ & .6266 \\
\hline Mediastinitis (no.) & $5(1.5 \%)$ & $1(0.6 \%)$ & $4(2.6 \%)$ & .1870 \\
\hline
\end{tabular}

ITA, Internal thoracic artery; $L A D$, left anterior descending coronary artery.

$(P=.1477)$. There were 2 patients with recurrent angina and 4 with congestive heart failure in the individual group. There were 5 patients with recurrent angina and 4 with congestive heart failure in the sequential group.

\section{Angiographic Outcomes}

The patency rates of both groups at early and follow-up angiographic studies are listed in Table 4. The overall patency rates of distal anastomosis of the free RITA were $99.1 \%$ at early angiography and $91.8 \%$ at follow-up angiography. According to the $\chi^{2}$ test, there were no significant differences in the early $(P=.6055)$ and follow-up $(P=.7896)$ patency rates between the individual grafting group and the sequential grafting group. According to generalized estimating equations, there were no significant differences between the 2 groups in the early (odds ratio of sequential grafting, $0.50 ; 95 \%$ confidence interval, $0.05-5.62 ; P=.577$ ) or follow-up (odds ratio of sequential grafting, 1.36; 95\% confidence interval, 0.46-4.00; $P=.580)$ patency rates.

The patency rates of the in situ RITA were 99.3\% (575/ $579)$ at early angiography and 94.6\% (384/406) at followup angiography. The patency rates of the free RITA at early $(P=.7273)$ and follow-up $(P=.2020)$ angiography were similar to those of the in situ RITA.

In the individual grafting group, there were 6 occluded anastomoses $(6 / 86 ; 7 \%)$. The target coronary arteries had a low stenosis rate $(<75 \%)$ in 3 of them $(3 / 6 ; 50 \%)$.
There were 10 target coronary arteries with a low stenosis rate in patent anastomoses $(10 / 80 ; 12.5 \%)$. The occluded anastomoses had a significantly lower stenosis rate in the target coronary artery than did the patent anastomoses $(P=.0420)$. In other words, the occlusion rate of the RITA distal anastomoses was higher for target vessel stenosis less than $75 \%$ in the individual grafting group.

In the sequential grafting group, there were 16 occluded anastomoses $(16 / 182 ; 9 \%)$. The target coronary arteries had a low stenosis rate in 5 of them $(5 / 16 ; 31 \%)$. There were 11 target coronary arteries with a low stenosis rate in patent anastomoses $(11 / 166 ; 66 \%)$. Of those, 3 were the most distal target arteries for the free RITA. The occluded anastomoses had a significantly lower stenosis rate in the target coronary artery than did the patent anastomoses $(P=.0067)$. In other words, the occlusion rate of the RITA distal anastomoses was higher for target vessel stenosis less than $75 \%$ in the sequential grafting group.

In the individual group, the proximal anastomosis site (aorta or other grafts) did not affect the patency rate of either early $(100 \%$ vs $98.0 \% ; P>.9999)$ or follow-up $(89.3 \%$ vs $94.8 \% ; P=.3860)$ angiographic studies.

There was no difference in the patency rate of anastomoses of inflow conduits of free RITA between the 2 groups $(89.7 \%$ vs $91.1 \% ; P=.7633)$ in follow-up angiography.

The follow-up angiographic studies included 9 patients with symptoms ( 7 with angina and 2 with heart failure). 

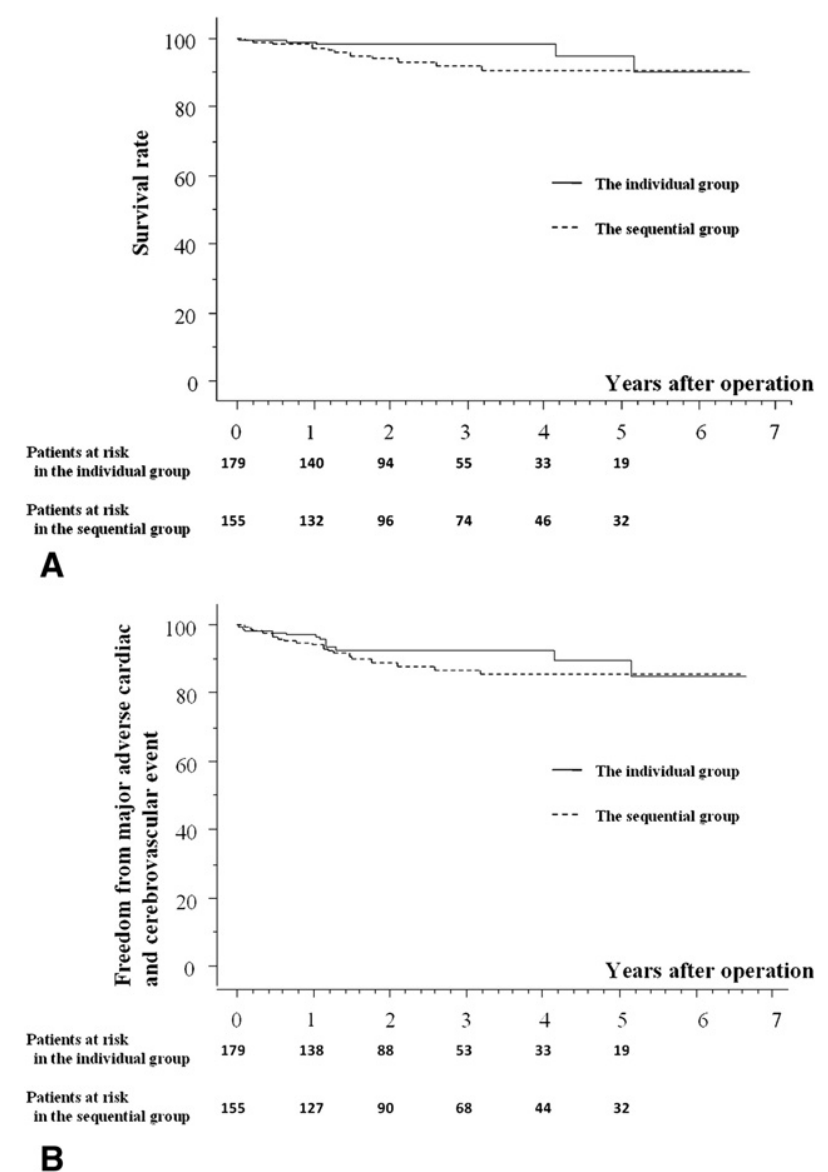

FIGURE 1. A, Survival curve comparing the individual grafting group (solid line) with the sequential grafting group (dashed line) by the Kaplan-Meier method. B, Kaplan-Meier curve comparing freedom from major adverse cardiac and cerebrovascular events in the individual grafting group (solid line) with that in the sequential grafting group (dashed line).

Among those patients, percutaneous coronary intervention was performed in 4 patients. Percutaneous coronary intervention was also performed in 10 patients without symptoms because of graft occlusion in 6 patients and new native coronary stenosis in 4 patients.

Patency rates of the free RITA were also compared with those of other grafts. Early patency rates of the LITA, radial artery, gastroepiploic artery, and saphenous vein graft were $99.6 \%, 99.1 \%, 100 \%$, and $95.8 \%$, respectively. Follow-up patency rates of the LITA, radial artery, gastroepiploic artery, and saphenous vein graft were $100 \%, 69.4 \%$, $88.9 \%$, and $87.4 \%$, respectively. The generalized estimating equations showed no difference in early (odds ratio of the free RITA, 0.39 ; 95\% confidence interval, 0.10-1.52; $P=.176)$ and follow-up (odds ratio of the free RITA, $1.23 ; 95 \%$ confidence interval, $0.61-2.43, P=.558$ ) patency rates between the free RITA and other grafts.

Figure 1, $B$ shows freedom from major adverse cardiac and cerebrovascular events (death, stroke, myocardial infarction, and revascularization) during the follow-up period.
TABLE 4. Cumulative angiographic patency rates of the free right internal thoracic artery graft

\begin{tabular}{lcc}
\hline & Early $(\mathbf{n}=\mathbf{2 7 0})$ & Follow-up $(\mathbf{n}=\mathbf{1 7 0})$ \\
\hline Total & $418 / 422(99.1 \%)$ & $246 / 268(91.8 \%)$ \\
Individual & $140 / 142(98.6 \%)$ & $80 / 86(93.0 \%)$ \\
Sequential & $278 / 280(99.3 \%)$ & $166 / 182(91.2 \%)$ \\
$\quad$ Double & $210 / 212(99.1 \%)$ & $129 / 142(90.8 \%)$ \\
Triple & $60 / 60(100 \%)$ & $33 / 36(91.7 \%)$ \\
Quadruple & $8 / 8(100 \%)$ & $4 / 4(100 \%)$ \\
\multicolumn{2}{l}{ Entries indicate number of patent grafts per number of grafts examined in group, with } \\
associated percentage.
\end{tabular}

There was no difference in the rate of major adverse cardiac and cerebrovascular events between the groups $(P=.3086)$.

\section{DISCUSSION}

This study demonstrated that sequential grafting with the free RITA for multiple anastomoses of the left coronary artery was safe and effective, with identical early and followup patency rates to those in individual grafting with the free RITA.

Because the RITA is anatomically the same as the LITA, a longer patency rate of the RITA is expected than in other grafts. Because the length of the RITA when it is used as an in situ graft is sometimes not sufficient for revascularization for lateral vessels; however, a free graft with proximal anastomoses to the aorta or other grafts has been used. ${ }^{8}$ The RITA is almost always nonatherosclerotic and flexible, but sequential grafting with the free RITA is considered to be more complex because it is smaller and shorter than other grafts. We believe that skeletonization of the graft makes it longer and easier to handle than are nonskeletonized grafts. The blood flow of a skeletonized ITA is reported to be greater than that of a pedicled ITA. ${ }^{9}$ It can reach the posterior descending coronary artery with composite grafting when its proximal anastomosis is carried out on the LITA. ${ }^{10}$ We did not use the free RITA for revascularization of the right coronary artery because of an inferior patency rate compared with that for the left coronary artery. ${ }^{11}$

The free RITA was mainly used for revascularization of the circumflex artery (obtuse marginal or left posterolateral branch). When there was only a single stenosis of the circumflex artery, the free RITA was used individually. When there were 2 or more stenoses of the circumflex artery, the free RITA was anastomosed sequentially. In that case, however, the size of the branches and the degree of the stenosis affected the strategy. If the size of multiple branches was greater than $1.0 \mathrm{~mm}$ or 1 of the multiple branches had a diameter greater than $2.0 \mathrm{~mm}$, the free RITA was individually anastomosed to this large vessel. The other circumflex branches were revascularized with a radial artery or saphenous vein graft. Individual grafting with the free RITA for revascularization of the anterior vessels (left anterior descending coronary artery or diagonal 
branch) was performed when the LITA was not useful or it was used for lateral vessels because the quality of the LITA was inferior to that of the RITA.

In this study, patients in the sequential grafting group had more diseased vessels than did those in the individual group. This led to a larger number of distal anastomoses in the sequential grafting group than in the individual grafting group. We could perform multiple distal anastomoses of lateral vessels with the sequential grafting technique with the free RITA without increasing the total number of grafts (3.4 grafts per patient in the individual grafting group and 3.3 in the sequential grafting group).

In this study, the proximal anastomosis site of the free RITA used as an individual grafting was at the aorta $(27.4 \%)$, the LITA $(16.2 \%)$, and other grafts $(56.4 \%)$. Conversely, the proximal anastomosis site of the free RITA used as a sequential graft was performed only at the LITA $(50.3 \%)$ and other grafts $(49.7 \%)$. When we used the free RITA as a sequential graft, proximal anastomosis usually did not reach the aorta. The proximal anastomosis site (aorta or other grafts) did not affect the patency rate of either early or follow-up angiographic studies. We believe that composite grafting to other grafts is safe and effective when the native stenosis is significant. ${ }^{12}$ In the individual grafting and sequential grafting groups, 50\% (3/6) and $31.3 \%(5 / 16)$ of occluded anastomoses, respectively, had a low stenosis rate $(<75 \%)$. We currently use a free RITA only for a target vessel with greater than $75 \%$ stenosis.

There have been several reports comparing the patency rates between the in situ RITA and the free RITA., ${ }^{4,5,13-15}$ Recently, Tatoulis and colleagues ${ }^{3}$ demonstrated excellent late patency rates of the RITA (overall 10-year patency rate was $90 \%$ ). Furthermore, patency rates of in situ and free RITAs were almost identical. Tatoulis and colleagues, ${ }^{3}$ however, did not include sequential grafting of the free RITA in the analysis. In our study, both early and followup angiographic results in the sequential grafting group were as good as those in the individual grafting group. The target coronary arteries had a low stenosis rate in 8 anastomoses ( 3 in the individual group and 5 in the sequential group) in a total 22 occluded anastomoses. Competitive or reverse flow as a result of a low stenosis rate could be the potential cause of occlusion. ${ }^{12}$

This clinical study has the following limitations. First, it was a retrospective observational study and not randomized. In addition, we could not follow up all patients with free RITA grafts. Furthermore, early and follow-up angiography were not performed in all patients (early, 80.8\%; follow-up, $50.9 \%$ ). Patients who did not undergo angiography were older and had more renal deficiency than did those undergoing angiography. Our findings may not be applicable in patient groups such as the elderly and patients with renal insufficiency who did not have a follow-up angiogram. We used the SPY imaging system (Novadaq Technologies Inc, Toronto, Ontario, Canada) and a Doppler flowmeter for the graft patency assessment during the operation. Although no graft occlusion was observed during operation, we did not compare these results and the angiographic results in this study.

In conclusion, sequential grafting with the free RITA can be performed safely. Patency rates of individual and sequential grafting with the free RITA are almost identical. Because the patencies of distal anastomoses were similar between the individual and sequential grafting groups, the overall number of patent anastomoses was greater in the sequential grafting group. When the RITA cannot be used as an in situ graft for multiple anastomoses, the free RITA with sequential grafting should be considered.

\section{References}

1. Loop FD, Lytle BW, Cosgrove DM, Stewart RW, Goormastic M, Williams GW, et al. Influence of the internal-mammary-artery graft on 10-year survival and other cardiac events. N Engl J Med. 1986;314:1-6.

2. Taggart DP, D'Amico R, Altman DG. Effect of arterial revascularization on survival: a systematic review of studies comparing bilateral and single internal mammary arteries. Lancet. 2001;358:870-5.

3. Tatoulis J, Buxton BF, Fuller JA. The right internal thoracic artery: the forgotten conduit-5,766 patients and 991 angiograms. Ann Thorac Surg. 2011;92:9-17.

4. Kim KB, Cho KR, Chang WI, Lim C, Ham BM, Kim YL. Bilateral skeletonized internal thoracic artery graftings in off-pump coronary artery bypass: early result of Y versus in situ grafts. Ann Thorac Surg. 2002;74:S1371-6.

5. Glineur D, Hanet C, Poncelet A, D'hoore W, Funken JC, Rubay J, et al. Comparison of bilateral internal thoracic artery revascularization using in situ or Y graft configurations: a prospective randomized clinical, functional, and angiographic midterm evaluation. Circulation. 2008;118(14 Suppl):S216-21.

6. Fukui T, Takanashi S, Hosoda Y, Suehiro S. Early and midterm results of offpump coronary artery bypass grafting. Ann Thorac Surg. 2007;83:115-9.

7. Fukui T, Tabata M, Taguri M, Manabe S, Morita S, Takanashi S. Extensive reconstruction of the left anterior descending coronary artery with an internal thoracic artery graft. Ann Thorac Surg. 2011;91:445-51.

8. Pevni D, Uretzky G, Mohr A, Braunstein R, Kramer A, Paz Y, et al. Routine use of bilateral skeletonized internal thoracic artery grafting: long-term results. Circulation. 2008;118:705-12.

9. Gurevitch J, Kramer A, Locker C, Shapira I, Paz Y, Matsa M, et al. Technical aspects of double-skeletonized internal mammary artery grafting. Ann Thorac Surg. 2000;69:841-6.

10. Navia D, Vrancic M, Vaccarino G, Piccinini F, Raich H, Florit S, et al. Total arterial off-pump coronary revascularization using bilateral internal thoracic arteries in triple-vessel disease: surgical technique and clinical outcomes. Ann Thorac Surg. 2008;86:524-30.

11. Buxton BF, Ruengsakulrach P, Fuller J, Rosalion A, Reid CM, Tatoulis J. The right internal thoracic artery graft - benefits of grafting the left coronary system and native vessels with a high grade stenosis. Eur J Cardiothorac Surg. 2000;18:255-61.

12. Manabe S, Fukui T, Tabata M, Shimokawa T, Morita S, Takanashi S. Arterial graft deterioration one year after coronary artery bypass grafting. J Thorac Cardiovasc Surg. 2010;140:1306-11.

13. Calafiore AM, Contini M, Vitolla G, Di Mauro M, Mazzei V, Teodori G, et al. Bilateral internal thoracic artery grafting: long-term clinical and angiographic results of in situ versus Y grafts. J Thorac Cardiovasc Surg. 2000;120:990-6.

14. Lev-Ran O, Paz Y, Pevni D, Kramer A, Shapira I, Locker C, Mohr R. Bilateral internal thoracic artery grafting: midterm results of composite versus in situ crossover graft. Ann Thorac Surg. 2002;74:704-11.

15. Fukui T, Tabata M, Manabe S, Shimokawa T, Morita S, Takanashi S. Angiographic outcomes of right internal thoracic artery grafts in situ or as free grafts in coronary artery bypass grafting. J Thorac Cardiovasc Surg. 2010;139:868-73. 